\title{
Representação social sobre saúde em uma escola no Rio de J aneiro
}

http://dx.doi.org/10.11606/1807-5509202000040611
Laila Maria Cardoso Zalfa*

Giannina do Espirito-Santo**

Monique Ribeiro de Assis*
*Universidade do Estado do Rio de Janeiro, Rio de Janeiro, RJ, Brasil. * Centro Universitário Augusto Motta, Rio de Janeiro, RJ, Brasil.

\section{Resumo}

0 objetivo do estudo foi identificar a representação social sobre saúde em um grupo formado por 186 jovens que cursavam o segundo ano do ensino médio em uma escola localizada no município do Rio de Janeiro. 0 estudo foi realizado no ano de 2016 e os dados foram coletados a partir de evocações livres ao termo indutor saúde. Para tal, utilizou-se a Teoria das Representações Sociais (TRS) elaborada por Moscovici, em especial, a técnica de associação livre de ideias baseada na Teoria do Núcleo Central (TNC) proposta por Jean Claude Abric. Os resultados encontrados em um primeiro momento apontaram para uma representação baseada em uma perspectiva biofisiológica da saúde, na qual o elemento central revelado foi Hospital, e os elementos periféricos de maior representatividade foram: Médico, Bem-estar, Exercício, Alimentação e Precariedade. Concluiu-se que a representação de saúde para o grupo estava subordinada principalmente a um contexto social medicalizado, em que as práticas corporais entendidas como saudáveis formavam o pano de fundo para interação com o mundo da estética. Finalizando, notou-se uma dicotomia existente entre a saúde privada e a pública, o que torna essa representação uma questão mais de caráter socioeconômico do que propriamente biológico.

Palavras-Chave: Jovens; Ensino Médio; Abordagem Estrutural; Medicalização.

\section{Introdução}

A forma como o indivíduo percebe e sente seu corpo reflete os valores do seu tempo. Tais percepçóes estão atreladas aos sentidos atribuídos ao corpo pela cultura e pelo momento histórico. O corpo que reflete os valores contemporâneos caracteriza-se pelo imperativo da "saúde" e por uma estética que busca o liso, o magro e um desenho das formas cuja ênfase reside no contorno e torneamento dos músculos e nos procedimentos químicos e cirúrgicos ${ }^{1}$.

Além disso, existe uma grande campanha midiática, que partilha e divulga a ideia que ser saudável é ser magro, ativo fisicamente, ter uma alimentaçáo hipocalórica e balanceada ${ }^{2}$. Diante disso, o principal indicador visível utilizado popularmente para julgar se o indivíduo é ou não portador de saúde tornou-se a sua aparência física juntamente com suas taxas de colesterol, triglicerídeos, glicose e uma lista cada vez maior que cresce com o aperfeiçoamento da indústria farmacêutica.

Nesse sentido, o ideal de saúde na modernidade tornou-se uma busca inalcançável, uma vez que ela exige do sujeito a certeza absoluta de estar sempre em constante equilíbrio ${ }^{3}$. Desse modo, a instauração da medicina moderna tem cumprido o papel de controlar a sociedade num processo de crescente medicalização ${ }^{a}$ de todas as categorias da vida ${ }^{4-6}$.

Nessa perspectiva, percebe-se que a saúde é um fator determinante de integraçáo na sociedade, ao mesmo tempo que doença é considerada como agente de exclusão, deste modo, o corpo enquanto detentor tanto da saúde quanto da doença possui implicaçôes sociais para além das ameaças biológicas? ${ }^{7}$. Isso significa que nos dias atuais, muitas das decisões e dos hábitos que os indivíduos passaram a desfrutar 
no seu cotidiano para manter um equilíbrio salutar são julgados dentro de uma norma imperativa na qual os cuidados com a saúde se manifestam através dos corpos saudáveis e bonitos. Isso acontece porque a partir do discurso médico, dietético e estético, os indivíduos percebem a educação das práticas corporais como um veículo que o possibilita compreender sua concepção de corpo na modernidade ${ }^{1}$.

Segundo SOAREs ${ }^{8}$, a educação dos corpos enquanto depositário de normas e disciplina foi marcado e internalizado por condutas e gestos contidos, que atualmente continuam influenciando diretamente as relaçôes que indivíduos, principalmente os jovens passam a ter com as diferenças visíveis inscritas nos seus próprios corpos e no dos outros ${ }^{8}$.

Ainda de acordo com a autora, nos dias de hoje, a ordem social manifesta-se através de várias normas estratégicas e uma delas se encontra presente em modelos vinculados à saúde, higiene e à qualidade de vida realizados nos próprios ambientes educacionais. Tais modelos normativos influenciam diretamente as relaçóes que jovens passam a ter com as diferenças visíveis inscritas nos seus próprios corpos e no dos outros.

Diante disso entende-se que a escola é a instituiçāo central na vida de crianças e jovens nas construçôes das identidades, pois, nesse espaço, os alunos são socializados com variadas normas e técnicas no sentido amplo do termo como, por exemplo, vestimentas, conhecimentos, experiências com técnicas motrizes e expressivas, normas de conduta e cuidados corporais ${ }^{8,9}$.

Uma vez que a escola é um espaço que reúne todas essas características, tratar temas como esse de forma responsável torna-se necessário. É importante formar as novas geraçóes com saberes e técnicas que auxiliem a manter a saúde dos corpos para além das novas subjetividades forjadas no século XXI que acabam se tornando, de alguma maneira, fonte de angústia, culpa ou preconceito?.

Portanto, esse é um tema contemporâneo que coloca a escola como um espaço privilegiado para problematizar práticas cotidianas e promover reflexôes sobre as representaçóes a respeito da saúde entre jovens no ambiente escolar. Pensar questóes dessa natureza nesse espaço tem por intenção calibrar nosso olhar pedagógico para entender como as normatividades a respeito da educaçáo dos corpos são instituídos no imaginário coletivo escolar como um currículo "oculto", o que deve fazer emergir os aspectos interditos do currículo?.

Considerando o exposto, o objetivo desse estudo foi identificar as representaçóes sociais de jovens escolares sobre saúde, tendo como referência os processos simbólicos que se manifestam na realidade destes indivíduos. Nesse caso, a Teoria da Representação Social (TRS) foi o referencial orientador da pesquisa, pois exerce essa função em relação ao tema a medida que, permite a realização do conhecimento individual e o social para refletir sobre comportamentos e construir novos olhares sobre a saúde na contemporaneidade. Desse modo, pensar representação social sobre a saúde expressa entender a esfera no qual os jovens estáo inseridos, juntamente com as construçóes decorrentes de suas interaçóes sociais.

\section{Teoria da Representação Social TRS}

Essa teoria surgiu na França em 1961 por meio de Serge Moscovici e de acordo com o autor, a representação social é um conjunto de conceitos, proposiçóes e explicaçóes originadas na vida cotidiana no curso de comunicaçóes interpessoais. Segundo ele, as representaçóes sociais sáo o equivalente, em nossa sociedade, dos mitos e sistemas de crenças, do qual podem ser vistas como a versão contemporânea do senso comum ${ }^{10}$. Deste modo, ele esclarece que o estudo da TRS tenta compreender o que acontece quando a ciência da Psicanalise passa do domínio dos grupos especializados para o domínio do senso comum. Desde então, introduziu-se um campo de estudos inovador no âmbito da Psicologia Social no qual buscou, sobretudo, redefinir os problemas dessa ordem a partir do fenômeno das representaçóes reiterado na sua função simbólica de construção do real ${ }^{11}$.

Partindo do pressuposto que a TRS é um marco conceitual no qual trabalha o campo das produçôes simbólicas a respeito do cotidiano, Moscovici ${ }^{10}$ ressalta que essas produçóes não devem ser compreendidas em termos comuns, ou seja, vulgarizados ou distorcidos, pois referem-se de um saber adaptado a outras necessidades no qual submetem-se a outros critérios.

De acordo com ARrudA ${ }^{12}$, Moscovici ${ }^{10}$ recupera, através da TRS o saber do senso comum, antes avaliado de forma desordenada e confusa. Para SPINK ${ }^{13}$, esse campo de saber não se trata apenas de reabilitação do senso comum como forma de conhecimento válido, mas, acima de tudo, trata-se "de situá-lo enquanto teia de significados (...) capaz de criar efetivamente a realidade social". JODELET ${ }^{14}$ afirma que sua especificidade, apoiada por fins sociais, representa um instrumento de estudo 
epistemológico legitimo e necessário para entender os mecanismos do pensamento.

Ainda sobre a TRS, cabe esclarecer que se apresenta em três perspectivas: a primeira liderada por Denise Jodelet é orientada pela teoria original constituída de um viés mais antropológico; a segunda segue as recomendaçóes de Willen

\section{Método}

\section{Participantes}

Participaram do estudo jovens estudantes matriculados no segundo ano do ensino médio de uma escola particular localizada na cidade do Rio de Janeiro no ano de 2016. A instituição escolar possui duas unidades, uma situada no bairro da Gávea, zona Sul da cidade, um dos locais mais valorizados do município ${ }^{\text {b }}$ e a outra localizada na Barra da Tijuca, zona Oeste, bairro que se caracteriza por ser o destino de grande parte dos chamados "novos ricos"c Para o desenvolvimento do estudo, constituímos uma amostra de 186 alunos sendo composta de 83 alunos da unidade Barra da Tijuca e 103 da unidade Gávea. Vale lembrar que a pesquisa foi constituída com alunos de ambos os sexos e idades entre 15 e 18 anos. A opção por essa instituição com duas unidades, apesar de se localizarem em bairros distintos teve como propósito a inserção de uma amostra homogênea que fosse formada por adolescentes da mesma classe social.

Os critérios usados para a inclusão dos alunos no estudo foi a sua disposição para participar da pesquisa, assinando o termo de consentimento livre e esclarecido ou trazendo o termo de assentimento assinado por um responsável. Além disso, os alunos deveriam estar cursando o segundo ano do ensino médio, logo dentro da faixa etária estipulada. Deste modo, os alunos que não possuíam tais características, não assinaram, não trouxeram os referidos termos assinados, ou por algum motivo não se sentiram à vontade para responder as questóes propostas pelo pesquisador foram excluídos do estudo.

O estudo foi submetido ao Comitê de Ética em pesquisa do Hospital Pedro Ernesto. Os participantes da pesquisa registraram sua participação através da assinatura em um termo de assentimento oferecido aos seus respectivos responsáveis, sob o CAAE: 57851715.0 .0000 .5259 .
Doise, que apesar de se basear na teoria original, é orientada por uma perspectiva mais sociológica; a terceira é chamada de Teoria do Núcleo Central. A última foi que tomamos como base para orientar o estudo em questão, pois enfatiza a dimensão cognitivo-estrutural das representaçóes e tem como representante Jean-Claude Abric ${ }^{11}$.

\section{Instrumento}

\section{Abordagem Estrutural}

A principal teoria da abordagem estrutural é a Teoria do Núcleo Central, essa defende que as representaçóes sociais são um duplo sistema formado por dois tipos de elementos. Segundo Abric ${ }^{15}$, toda representação se organiza em torno de um núcleo central e um sistema periférico. $\mathrm{O}$ núcleo central é um elemento fundamental da representação social, pois é ele quem determina ao mesmo tempo sua significação e sua organização. Deste modo, o núcleo central constitui a base comum e consensual de uma representação social, aquela que resulta da memória coletiva do sistema de normas ao qual certo grupo se refere, constituindo-se em prescriçóes absolutas. Portanto constitui o elemento mais sólido das representaçóes, aquele que assegura a permanência em contextos mais móveis. $\mathrm{O}$ sistema periférico, ao contrário do central, é mais flexível, pois suporta as contradiçóes e, assim, protege o núcleo central das modificaçôes. Deste modo, se torna a parte mais maleável das representações sociais e com isso, permite a elaboração de representaçóes relacionadas às histórias individuais dos sujeitos ${ }^{11}$.

Seguindo com o estudo, utilizou-se a técnica de análises de evocaçóes ou quadro de quatro casas, de acordo com VERGÈs ${ }^{16}$, essa constitui-se em duas etapas: a primeira, chamada de análise prototípica, consiste em calcular a frequência e as ordens das evocaçóes das palavras e a segunda se encarrega de formular as categorias reunidas nas evocaçóes, bem como avaliar suas frequências, composiçóes e suas co-ocorrências. Tal estratégia foi elaborada com a finalidade de caracterizar a estrutura da RS a partir de evocaçóes das palavras ${ }^{17}$.

De acordo com vários autores, esse processo configurou-se um dos mais populares para estudar RS em pesquisas de base ${ }^{18,19}$, pois a estratégia, parte do princípio que os elementos da RS de valor relevante em sua estrutura são mais prototípicos, ou seja, são 
mais acessíveis à consciência. O método em questão consiste em uma investigação aberta que se estrutura a partir da evocação de respostas dadas com base em um estímulo indireto, o que permite colocar em evidência o universo semântico relacionados a um determinado objeto.

No presente estudo, buscou-se fazer uma análise estrutural das evocaçôes livres dos estudantes sobre saúde. Para isso, solicitou-se aos participantes que escrevessem as quatro primeiras palavras que lhes viessem imediatamente à lembrança quando ouvissem o termo indutor Saúde. De acordo com $S_{A^{11}}{ }^{11}$ o fato de ser espontâneo permite chegar às representaçóes imediatas sobre o objeto estudado.

\section{Procedimentos}

\section{Quadro de quatro casas}

Em um primeiro momento foi organizada a estrutura que corresponde ao quadro de quatro casas, isto é, um conjunto de elementos que compóem respectivamente, o núcleo central e o sistema periférico das representaçôes. Deste modo, o produto obtido através das evocaçóes livres foi analisado por meio dessa técnica. Para a interpretação da estrutura, seguiu-se os seguintes procedimentos baseados em $\mathrm{SA}^{11}$, no primeiro quadrante, no alto e à esquerda, situam-se os elementos mais (+) relevantes, portanto possíveis de constituírem o núcleo central de uma representação. A zona do núcleo central compreende as palavras com alta frequência e baixa ordem de evocação, ou seja, são as respostas fornecidas por um grande número de participantes e evocadas prontamente. As palavras localizadas no quadrante superior direito correspondem a $1^{\circ}$ periferia, essa zona inclui respostas com alta frequência e alta ordem de evocação. Segundo ABRIC ${ }^{15}$, são respostas com destaque, porém indicam elementos secundários.

\section{Resultados}

O resultado da primeira amostra possibilitou a criação do processo de formação das seguintes categorias: Hospital, Bem-estar, Médico, Alimentação, Exercício, Precariedade, Remédio, Doença, Infraestrutura, Morte e Outros. Após uma análise mais detalhada, optou-se em excluir o termo indutor mais baixo que no caso, foi o elemento "outros", com isso buscou-se clarificar os sentidos que
As palavras localizadas no quadrante inferior direito correspondem a $2^{\circ}$ periferia, nessa zona estâo incluídos os elementos com frequência de evocaçóes inferiores ao ponto de corte, são elementos evocados como últimas respostas, portanto menos interessantes. E o quadrante inferior esquerdo representa a zona de contraste, lá estão localizadas as respostas minoritárias que podem indicar duas circunstancias, a primeira indica apenas um complemento da primeira periferia e a outra pode ser identificada como um subgrupo que valoriza continuamente alguns elementos distintos da maioria ou até mesmo, como um núcleo central distinto ${ }^{15}$.

O material oriundo do teste de evocação foi tratado por meio do cálculo da frequência e da ordem média das evocações OMES. Considerando que a frequência é a soma do número de vezes que cada palavra foi evocada, a determinação dos quadrantes se deu através da média da soma de todas as frequências pela média da soma de todas as OMES. Já a OME foi calculada por meio da soma da média ponderada MP, dividida pelo valor da frequência. $\mathrm{O}$ cálculo da MP foi realizado através do resultado da soma da frequência em que o valor 1 é atribuído às respostas que foram fornecidas em primeiro lugar, o valor 2, para as respostas geradas em segundo lugar, o valor 3, para as respostas proferidas em terceiro lugar e assim sucessivamente.

$\mathrm{Na}$ sequência foram formuladas as categorias reunidas por critérios semânticos dos termos, isto é, foram agrupadas e classificadas por meio de um significado comum. Cabe ressaltar que esse instrumento é um importante facilitador para a análise da estrutura e organização de uma representação social ${ }^{17}$. Essa técnica foi escolhida porque permite colocar em evidência o objeto semântico do objeto estudado, assim como a sua dimensão imagética de forma mais rápida e dinâmica que outros métodos mais comuns e com igual objetivo como, por exemplo, a entrevista ${ }^{15}$. fomentaram o surgimento dos elementos centrais.

De acordo com o resultado das análises, Hospital foi apontado como elemento central, apresentando uma Frequência $=94, \mathrm{OME}=2,10 . \mathrm{Na}$ sequência, observou-se os elementos Bem-estar, Médico, Alimentação e Exercício reforçando o núcleo central. E finalizando, encontramos Precariedade como elemento contrastante. 
A partir das evocaçóes produzidas pela representação da saúde entre os estudantes construiu-se um quadro de quatro casas com os seguintes pontos de corte: Ordem Média (OME)
$=2,52$; Frequência mínima $=23$; Frequência média $=67,09 ;$ Total de evocações $=744$. A visualização do quadro de quatro casas pode ser observada através da FIGURA 1.

FIGURA 1 - Quadro de quatro casas.

\begin{tabular}{|c|c|}
\hline NÚCLEO CENTRAL & $\begin{array}{l}\qquad 1^{\circ} \text { PERIFERIA } \\
\text { Bem-estar FREQ }=110 ; \text { OME }=2,83 \text { ) } \\
\text { Médico (FREQ }=68 ; \text { OME }=2,35 \text { ) } \\
\text { Alimentaçäo (FREQ }=123 ; \text { OME }=2,39 \text { ) } \\
\text { Exercicio (FREQ=94; OME }=2,25 \text { ) }\end{array}$ \\
\hline Precariedade (FRQ $=54 ; \mathrm{OME}=2,40)$ & $\begin{array}{l}\text { 20 PERIFERIA } \\
\text { Remédio (FREQ }=53 ; \text { OME }=2,69 \text { ) } \\
\text { Doença (FREQ }=63 ; \text { OME }=2,82 \text { ) } \\
\text { Morte (FREQ }=29 ; \text { OME }=2,62 \text { ) } \\
\text { Infraestrutura (FREQ }=27 \text { OME }=2,62 \text { ) }\end{array}$ \\
\hline
\end{tabular}

\section{Discussão}

Observando a distribuição do quadro através da FIGURA 1, um aspecto que chama atençáo referese ao fato do elemento Hospital ganhar destaque ao aparecer exclusivo no Núcleo Central. Considerando que hospital é um espaço organizador de caráter médico-social destinado em assegurar assistência médica completa, curativa e preventiva a população ${ }^{20}$, dois fatores despontam aos olhos: o primeiro diz respeito à associação da saúde com a presença concreta da doença e o segundo tendo a medicina como instância hegemônica para tratá-la.

De acordo com Czeresnia ${ }^{21}$, a doença e o corpo doente não foram ajustados em prol de um conhecimento neutro, mas, constituídos por um viés positivista, no espaço da clínica. Por sua vez, a medicina pensa saúde a partir de critérios de mensurabilidade nos quais saúde e doenças passam a ser diferenciados por variáveis clínicas e fisiológicas, o que tornam os discursos científicos impregnados de conceitos objetivos destinados, na maioria das vezes, a curar doenças e não a produzir saúde ${ }^{21}$.

Segundo $\operatorname{Rosen}^{22}$, a ligação entre a doença e a saúde aconteceu em função da articulação de duas perspectivas: a social e a cultural. $\mathrm{O}$ autor aponta que

A doença e a saúde são aspectos desta instabilidade onipresente, são expressóes das relaçóes mutáveis entre os vários componentes do corpo, entre o corpo e o ambiente externo no qual ele existe”. (p.77).

\section{Para FoucaulT ${ }^{23}$,}

o controle da sociedade sobre os indivíduos não se opera pela consciência ou pela ideologia, mas começa no corpo, com o corpo. Foi no biológico, no somático que, antes de tudo, investiu a sociedade capitalista” (p. 80).

A esse respeito, FocaulT $^{24}$ esclarece que houve um tempo em que a vida biológica dos indivíduos, juntamente com a saúde da nação tornaram-se o epicentro de um poder sobre a vida. Esse poder, o biopoder, enquanto elemento indispensável para o desenvolvimento do Estado moderno, se valeu do controle dos corpos como instrumento produtivo (disciplina); enquanto a população serviu para os 
ajustes referentes aos processos econômicos próprios da modernidade (biopolítica). Desse modo, o crescimento industrial, próprio da época e a força de trabalho passaram a ser primordiais para o desenvolvimento do capitalismo. Assim, a investigaçáo precisa da vida, das doenças, do nascimento, da velhice e da morte, tornaram-se indispensáveis para se pensar saúde na modernidade ${ }^{23,24}$. Em vista disso, a grande apropriaçáo dos modos de viver pela medicina moderna tornou-se responsável pela negação do sofrimento, dos conflitos e das angustias por parte dos indivíduos 5 .

Alguns autores ${ }^{4,5,25}$ ao analisarem a sociedade nos dias de hoje, constataram que vive-se um processo de crescente "apoderamento" pelo conhecimento médico, para eles tal prática atende as necessidades do homem moderno ao fornecer-lhes ferramentas que permitem controlar a engrenagem dos corpos com a finalidade de apresentar alívio aos seus sofrimentos. Em decorrência disso, transcorre a "hipertrofia" da medicalização da vida, pois, uma vez que o sujeito é identificado como doente, torna-se vítima e consequentemente consumidor de práticas que transformam o seu próprio corpo em alvo das questóes que, na lógica médica, deveriam ser tratadas individualmente.

O ponto chave dessa questão aconteceu quando problemas que sempre fizeram parte da vida comum dos indivíduos passaram a ser definidos através dos termos médicos, deste modo, explicados a partir dessa racionalidade, passaram a ser descritos a partir de uma linguagem médica e assim estabeleceram novas categorias de doenças que atualmente necessitam ser medicalizadas ${ }^{25}$.

Deste modo, ILLICH ${ }^{26}$ considera que a maior das patologias é causada pela doença iatrogênica. Nesse caso, ela é gerada justamente pela prevenção, pois visitamos especialistas e fazemos exames mesmo quando estamos nos sentindo bem.

De acordo com $S_{F E Z}{ }^{3}$, a saúde perfeita tornou-se o novo ideal de vida na atualidade e deste modo, ela exige do indivíduo a certeza de ser pleno e saudável. Em razão disso, torná-la visível de forma que possa ser ostentada determina consequentemente um meio de identidade subjetiva. $\mathrm{O}$ autor ainda esclarece que dispor de saúde para se levar uma vida plena não é o suficiente, pois, além disso, tem que manter-se vivo para dar sentido às "biotecnologias modernas" e, deste modo, restabelecer uma nova moral. Nesse sentido, o autor aponta que essa moral é a de se alimentar de forma correta ("Sem colesterol"); beber socialmente uma taça de vinho tinto ("Para o cuidado das artérias"); praticar sexo seguro ("Perigo da AIDS")

Dando sequencia às análises, outros elementos como Alimentação e Exercício também despontam na $1^{\circ}$ Periferia para oferecer sustentação ao núcleo central. A esse respeito vale lembrar que esses elementos representam práticas e açóes preventivas que levam a promoção de um estilo de vida saudável, ou seja, revelam escolhas que influenciam hábitos de vida que possibilitem gozar de boa saúde de acordo com a perspectiva "promocionista" da saúde ${ }^{27}$. FraGa $^{28}$, também realiza um debate nesse sentido, quando aborda sobre o mercado da informação existente para divulgar os benefícios da atividade física, a colocando em um papel de remédio e de salvadora dos males. A segunda periferia remete que os alunos podem ter sidos cooptados por esse "mercado do agita" como atribuído pelo autor, pois eles relacionam à saúde com os exercícios físicos, demonstrando de certa forma que eles foram persuadidos pela vida ativa, ao menos em discurso, que pode levar a uma vigília sobre os corpos, para o seu controle.

Esse cenário pode ser reforçado por inúmeras publicaçóes que procuram estabelecer uma relação de causa e efeito entre atividade física e saúde, tendo a atividade física como um remédio para esses males ${ }^{29-34}$.

Atualmente, náo há como desconsiderar o pressuposto de que a temática do corpo e suas representaçóes na modernidade formam o pano de fundo para dialogarmos com questóes ligadas à saúde. Tais demandas resultam, na maioria das vezes, na busca de um padrão corporal específico de beleza, no qual se solidifica uma série de comportamentos sobre estilos de vida saudável. Isso não quer dizer que a maioria das pessoas transformam suas açôes com relação a alimentação ou a prática de exercícios, mas a mudança de comportamentos está associada à aceitaçáo da norma - mesmo que esta seja distorcida na apropriaçáo popular - de que ser saudável é ser magro, ativo fisicamente e ter uma alimentação hipocalórica e balanceada. No entanto, não se pode desconsiderar que esse é um processo que está na esteira da modernidade e, deste modo traz, na passagem do século XIX para o XX, a temática do corpo e da beleza associada ao discurso da saúde e da estética ${ }^{1,27}$.

Outra característica observada na estrutura foi o surgimento do elemento Bem-estar dando sequencia a $1^{\circ}$ Periferia. Isso representa que, embora o primeiro entendimento de que saúde seria ausência de doença, não se pode deixar de considerar que outras perspectivas, tais como qualidade de vida por exemplo 
também estão se configurando como indicadoras de saúde no intuito de demarcá-la ${ }^{35,36}$.

De acordo com Buss ${ }^{35}$, a saúde vem estabelecendo novos cuidados e atenção ao conduzir suas açôes para um conhecimento mais voltado às praticas sociais, expandindo-se assim a um processo mais dinâmico e multifacetado pelo qual permite um entendimento mais amplo a respeito do fenômeno.

Entretanto, a noção de qualidade de vida é mais complexa ainda quando dispóem de uma responsabilidade que abrange ações políticas e econômicas, uma vez que o Índice de desenvolvimento humano (IDH) de um povo é medido por indicadores em que o grau de qualidade de vida está inserido ${ }^{36}$. De acordo com o PNUD ${ }^{e}$, o IDH é um indicador de qualidade de vida que, à grosso modo, soma e divide por três os níveis de renda, saúde e educação de determinada população. Partindo dessa ideia pode-se acrescentar que a qualidade de vida faz parte de um processo político econômico ${ }^{35}$.

É também nesse entorno que ganha espaço a reflexão sobre a presença do elemento Precariedade na Zona de Contraste da FIGURA 1. Se por um lado, esse elemento representa uma resposta minoritária, por outro, o seu surgimento merece uma análise mais expressiva, pois, duas alternativas despontam como relevantes: uma delas significaria que esses elementos seriam apenas um complemento da $1^{\circ}$ Periferia e a outra, que tais elementos poderiam ser identificados como um subgrupo, ou até mesmo poderiam ser considerados um Núcleo Central distinto ${ }^{37}$.

Sabe-se que a saúde está assegurada na constituição federal como um direito de todos, deste modo, o artigo 196 oferece a população o seguinte termo: "a saúde é direito de todos e dever do Estado, garantindo diante políticas sociais e econômicas que visem à redução de riscos de doenças e outros agravos e ao acesso universal e igualitários às açóes e serviços para a promoção, proteção e recuperação"f

Todavia, apesar das medidas, procedimentos e investimentos que as Políticas Públicas têm se esforçado em oferecer à população brasileira no sentido de estabelecer programas de saúde, é notório a falta de investimento no sistema. Isso pode ser observado tendo em vista os problemas enfrentados pela população - seja por abandono social ou desamparo - os quais têm sido gradativamente intensificados em face aos níveis da má qualidade de vida que colocam em vigilância o estado de saúde dos sujeitos. De certo modo nota-se que há por parte do grupo uma percepçáo da precariedade do sistema de saúde como um todo, porém essa realidade não pertence ao universo do qual eles fazem parte $^{38,39}$.

Finalizando as observaçóes, constatou-se na $2^{\circ}$ Periferia o surgimento dos seguintes elementos: Doença, Remédio, Morte e Infraestrutura. Tais evocaçóes indicam respostas minoritárias, pois essa zona na estrutura refere-se justamente aos elementos pouco proferidos nas duas coordenadas, portanto menos significativos para as representaçôes do grupo.

Dando prosseguimento as análises, segundo CANGuilheM $^{40}$, a doença anatomicamente pensada é algo produzido por meio de um desvio originalmente funcional, é um distúrbio das funções de um órgão ou organismo como um todo e está associada a sinais e sintomas específicos. Deste modo, com a construção de padróes normativos a respeito de se obter saúde, a medicina assumiu a definição desta como "normalidade" e a doença consequentemente como "anormalidade", estabelecendo assim com a fisiologia uma polaridade entre o normal e o patológico ${ }^{40}$.

Entretanto, conforme esclarece o autor, as normalidades estatísticas não são a base de onde se retira a norma da saúde ou da doença, pois, nem todo desvio em relação a esta normalidade implica doença. Esclarece ainda que ser normativo é ter capacidade de ampliar suas normas, suas regras biológicas, ou seja, de agir e reagir, de adoecer e se recuperar, ter a possibilidades de elaborar novas normas das exigências do meio. Já a doença implica na "redução da margem de tolerância às infidelidades do meio" (p.78) ${ }^{40}$.

Nesse caso, ele afirma que existem tantas normas biológicas sadias quanto as patológicas. Portanto, normalidade é igual a saúde mais doença. Tendo em vista que o normal não se caracteriza por um julgamento de realidade, mas de valores, nesse sentido pode-se dizer que patológico é o contrário de sadio e não de normal ${ }^{40}$.

Quanto ao elemento remédio, denota-se um recurso usado justamente na eliminação da dor e do sofrimento; o elemento morte trata-se do final da vida orgânica, ou seja, um processo que se torna irreversível; e o elemento infraestrutura refere-se a um conjunto de atividades e serviços públicos ou privados prestados a sociedade que são fundamentais para o desenvolvimento de um país.

Diante tais aspectos, pode-se dizer que a estrutura da representação de jovens sobre a saúde apontou para algumas questóes significativas que foram tratadas a seguir.

Em primeiro lugar constatou-se que esta foi subordinada principalmente às condiçóes que os submetem a uma perspectiva biofisiológica, na qual 
a dimensão saúde foi entendida como ausência de doença. Na sequência, constatou-se que o tratamento médico hospitalar se apresentou como o principal meio e recurso terapêutico. Deste modo, ficou claro o reconhecimento por parte do grupo em torno do valor do conhecimento médico, que domina nesse sentido, o poder e a responsabilidade de aliviar os sofrimentos e as angustias diante das ameaças de ficar doente.

Outra questão aferida foi a presença dos elementos Exercício e Alimentação que juntos formam o pano de fundo para interação com o mundo da estética, em que os cuidados com a saúde se manifestam através de corpos saudáveis e bonitos. Isso significa que, embora a saúde ainda seja entendida por aceitação de um modelo que parece nortear e influenciar não só a pesquisa científica, esta também é apresentada como mudanças de comportamento que se transforma na maioria das vezes em aceitação social.
Finalizando, constatou-se a existência de uma dicotomia entre a saúde privada e a pública, onde de um lado encontra-se uma saúde extremamente lucrativa e elitizada, que atende uma pequena camada da população, em que o elemento Hospital se destaca único como eixo central de sustentaçáo dessa representação e, do outro, uma estrutura de saúde que atende uma camada da população com precariedade de serviços, no qual deixa uma grande parcela de indivíduos desassistidos. O que torna essa representação uma questáo muito mais de caráter socioeconômico do que propriamente biológico.

Tendo em vista a necessidade constante de promover novas reflexōes pertinentes a essas questôes, seria interessante que trabalhos futuros se dedicassem a se aprofundar mais no fenômeno, de forma a abordar outros aspectos da representação social da saúde, como por exemplo, as diferentes estruturas sociais, políticas e econômicas do atual sistema de saúde.

\section{Notas}

a. Medicalização é um termo que surgiu em meados do século passado, criado pela sociologia da saúde para se referir à crescente apropriaçáo dos modos de vida do homem pela medicina.

b. Segundo a fonte http://oglobo.globo.com/economia/imoveis/os-cinco-bairros-mais-caros-do-pais-estao-na-zonasul-do-rio-7677088.

c. Disponível em: http://www.faperj.br/?id=1144.2.2

d. Um programa realizado em conjunto pela Secretaria de Estado da Saúde e do Centro de Estudos do Laboratório de Aptidão Física de São Caetano do Sul (CELAFICS) com a finalidade de desenvolver atividades físicas para combater o sedentarismo da população. Disponível em: http://www.cardiol.br/publicacao/jornalsbc/39/011.pdf e. É o órgão da Organização das Naçôes Unidas (ONU) que tem por mandato promover o desenvolvimento e eliminar a pobreza no mundo. É também conhecido por elaborar o Índice de Desenvolvimento Humano (IDH). f. Disponível em: http://conselho.saude.gov.br/14cns/docs/constituicaofederal.pdf 


\section{Abstract}

Social representation on health in a school in Rio de Janeiro.

The objective of the study was to identify the social representation on health in a group formed by 186 young people who were attending the second year of high school in a school located in the city of Rio de Janeiro. The study was conducted in the year 2016 and the data collected from free evocations to the term health inducer. For this, the Theory of Social Representations (TRS) elaborated by Moscovici was used, in particular, the technique of free association of ideas based on the Theory of the Central Nucleus (TNC) proposed by Jean Claude Abric. The results found at the outset pointed to a representation based on a biophysiological perspective of health, in which the central element revealed was Hospital, and the peripheral elements of greater representativeness were: Medical, Welfare, Exercise, Food and Precariousness. It was concluded that the health representation for the group was subordinated mainly to conditions that subject them to a medicalized social context, in which hospital medical treatment was presented as the main therapeutic resource. In the sequence it was observed that the corporal practices understood as healthy in this context, formed the background for interaction with the world of aesthetics. Finally, an existing dichotomy between private and public health has been noted, which makes this representation a more socio-economic rather than biological issue.

Kerwords: Young People; High School; Structural Approach; Medicalization.

\section{Referências}

1. Vigarello G. Treinar. In: Courtine JJ, organizador. História do corpo: as mutaçóes do olhar: O século XX. Petrópolis, RJ: Vozes, 2006. p. 197-250

2. Zalfa LMC, Candido CM, Assis MR. O sentido dos discursos sobre atividade física no jornal O Globo Online. Rev Bras Ci Mov. 2016; 24(2):15-25. Disponível em: https://portalrevistas.ucb.br/index.php/RBCM/article/ view/5770/4389.

3. Sfez L. A saúde perfeita: crítica de uma nova utopia. São Paulo: Loyola, 1996.

4. Clark J. Medicalization of global health 1: has the global health agenda become too medicalized? Global Health Action, 2014;7(1):1-6. Disponível em: http://www.tandfonline. com/doi/pdf/10.3402/gha. v7.23998\%40zgha20.2014.7.issue-s3?needAccess=true

5. Gaudenzi P, Ortega F. O estatuto da medicalização e as interpretações de Ivan lllitch e Michel Foucault como ferramentas conceituais para o estudo da desmedicalização. Interface Comunic Saúde Educ. 2011;16(40):21-34.

6. Ortega F. Biopolíticas da saúde: reflexões a partir de Michel Foucault, Agnes Heller e Hannah Arendt. Interface Cominic Saúde Educ. 2004;8(14):9-20. Disponível em: http://dx.doi.org/10.1590/S1414-32832004000100002.

7. Foucault M. Em defesa da sociedade. Curso no Collège de France. São Paulo: Martins Fonte, 2005.

8. Soares CL. Raízes europeias e Brasil. São Paulo: Autores Associados, 2007.

9. De Oliveira MAT; Linhales MA. Pensar a educação do corpo na e para a escola. Rev Bras Educ. 2011;16(47). Disponível em: http://www.scielo.br/pdf/rbedu/v16n47/v16n47a07.pdf

10. Moscovici S. A representação social da psicanálise. Rio de Janeiro: Zahar, 1978.

11. Sá CP. Núcleo Central das Representaçôes Sociais. Petrópolis: Vozes, 2002.

12. Arruda Â. A teoria das representaçóes sociais e teorias de gênero. Cad Pesquisa. São Paulo. 2009;117:127-147. 13. Spink MJ. O estudo das representaçóes sociais. In: Spink MJ, organizador. O conhecimento no cotidiano: as representações sociais na perspectiva da psicologia social. São Paulo: Brasiliense, 1995. p. 85-108.

14. Jodelet D. Representaçôes Sociais: um domínio em expansão. In: Jodelet D, organizador. As representaçôes sociais: Rio de Janeiro: EduUERJ. 2001.p.17-44.

15 Abric JC. A abordagem estrutural das representaçóes sociais. In: Moreira ASP, Oliveira DC. Estudos interdisciplinares de representação social. 2 ed. Goiânia: Ab, 2000. p. 27-46.

16. Vergès P, Tyszka T, Vergès, P. Noyau central, saillance et proprietés structurales. Papers Social Repres. 1994;3:3-12. 
17. Wachelke J, Wolter R. Critérios de construção e relato da análise prototípica para representaçóes sociais. Psicol Teor Pesq. 2001;27(4): 521-526.

18. Morin M, Vergès P. Enquête sur une représentation en voie d'émancipation: le sida pour les jeunes. Cahiers Intern Psychol Soc. 1992;15: 46-75.

19. Gurrieri C, Wolter RP, Sorribas E. L'implication personnelle: un outil psychosocial pour comprendre le lien population-objet. Psicol Estudo, 2007;12: 423-432.

20. Ornellas CP. Os hospitais: lugar de doentes e de outros personagens menos referenciados. R. Bras. Enferm,1998;51(2):253-262. Disponível em: http://www.scielo.br/scielo.php?pid=S0034$71671998000200007 \&$ script=sci_abstract\&tlng=p Acesso em: 24 Out. 2017.

21. Czeresnia D. The Concepto $f$ health and the diference between prevention and promotion. Cad Saúde Púb, 1999;15(4):701-709. Disponível em: http://www.scielo.br/pdf/csp/v15n4/1010.pdf. Acesso em: 20 de out. 2017.

22. Rosen G. Da Polícia Médica à Medicina Social. São Paulo: Unesp- Huicitec/Abrasco, 1974.

23. Foucault M. Microfísica do Poder. São Paulo: Paz e Terra, 1979.

24. Foucault M. História Da Sexualidade 1: A Vontade De Saber. Rio de Janeiro: Graal, 1999.

25. Nascimento MC, et al. A categoria racionalidade médica e uma nova epistemologia em saúde. Rev Ciênc Saúde Col, 2013;18(12):3595-3604. Disponível em: http://www.scielo.br/pdf/csc/v18n12/a16v18n12.pdf. Acesso em: 20 out. 2017.

26. Illich I. A expropriação da saúde. Nêmesis da medicina. Rio de Janeiro: Nova Fronteira, 1975.

27. Ferreira MS, Castiel LD, Cardoso MHCM. Atividade Física na perspectiva da nova Promoção da Saúde: contradiçôes de um programa institucional. Rev. Ciência \& Saúde Coletiva, 2009;16:865-872. Disponível em: http:// www.scielo.br/scielo.php?pid=S1413-81232011000700018\&script=sci_abstract\&tlng=pt. Acesso em: 20 dez 2017. 28. Fraga AB. Exercício da Informação: governo dos corpos no mercado da vida ativa. Campinas: Autores Associados, 2006.

29. Turi BC, Monteiro HL, Fernandes RA, Codgno JS. The impact of physical activity on mitgation of health care costs related to diabetes mellitus: Findings from developed and developing settings. Curr Diabetes Rev, 2016; 12(4):307-311. Disponível em: https://www.ncbi.nlm.nih.gov/pubmed/26472573. Acesso em: 3 mar. 2018.

30. Silva MAV da et all. Impacto da ativação da intenção na prática de atividade física em diabéticos tipo II: ensaio clínico randomizado. Rev Ciênc Saúde Col, 2015: 20(3): 875-886. Disponível em: http://www.scielo.br/scielo. php?script=sci_arttext $\&$ pid=S1413-81232015000300875\&lng=pt\&tlng=pt. Acesso em: 3 mar. 2018.

31. Santos AJCA et al. Effects of diabetes mellitus type I on skeletal muscle: An integrative review. J Morphologic Sci, 2016; 33(2):118-120. Disponível em: http://jms.org.br/PDF/v33n2a13.pdf. Acesso em: 3 mar. 2018.

32 . Reis RS et al. Scaling up physical activity interventions worldwide: Stepping up to larger and smarter approaches to get people moving. Lancet, 2016; 388(10051):1337-1348. Disponível em: http://www.thelancet.com/journals/ lancet/article/PIIS0140-6736(16)30728-0/fulltext. Acesso em: 3 mar. 2018.

33. Matsudo SM et al. The Agita São Paulo program as a model for using physical activity to promote health. Rev Panamerican Salud Publica/ Pan American J Public Health, 2003;14 (4):265-272. Disponível em: https://scielosp. org/article/rpsp/2003.v14n4/265-272/en/. Acesso em: 3 mar. 2018.

34. Ferrari CKB. Metabolic syndrome and obesety: Epidemiology and prevention by physical activity and exercise. J Exercise Sci Fitness, 2008;6(2):87-96. Disponível em: https:/www.scopus.com/record/display.uri?eid=2-s2.058149107490\&origin=inward\&txGid=9c45cd6fc20c6babef839a0901811414: Acesso em: 3 mar. 2018.

35. Buss PM. Promoção da saúde e qualidade de vida. Ciênc Saúde Coletiva, 2000;5(1):163-177

36. Minayo MCS, Hartz ZMA, Buss PM. Qualidade de vida e saúde: um debate necessário. Ciênc Saúde Col, 2000;5(1):7-18.

37. Abric JC. Práticas sociales y representaciones. México: Ediciones Coyoacán, 2001.

38. Paim J. A constituição cidadã e os 25 anos do Sistema Único de Saúde. In: Gomes IM, Fraga AB, Carvalho YM. Práticas corporais no campo da saúde: uma política em formação. Rede Unida: Porto Alegre, 2015, p. 21-46.

39. Buss PM, Pellegrine Filho A. A saúde e seus determinantes sociais. Physis, 2007;17(1):77-93.

40. Canguilhem G. O normal e o patológico. Rio de Janeiro: Forense Universitária, 2009. 


\begin{tabular}{r|l} 
ENDEREÇO & \\
Laila Maria Cardoso Zalfa & Submetido: 21/12/2017 \\
Rua Vilhena de Morais, 240, B2/ 402 & Revisado: 06/03/2018 \\
22793-140 - Rio de Janeiro - RJ - Brasil & Aceito: 07/ 05/2018 \\
E-mail: lailazalfa@yahoo.com.br & \\
&
\end{tabular}

